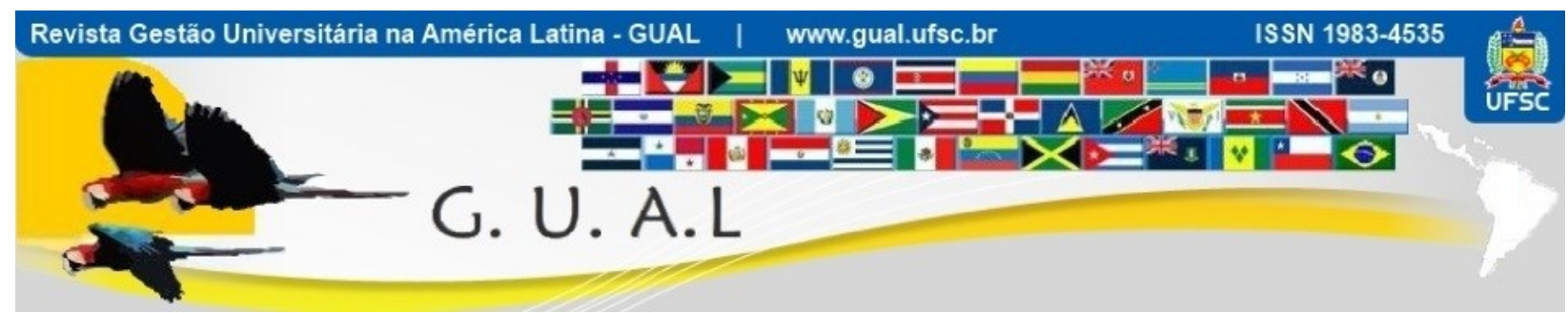

DOI: http://dx.doi.org/10.5007/1983-4535.2013v6n3p1

\title{
"MANAGERIALISM" NA GESTÃO UNIVERSITÁRIA: UMA ANÁLISE DE SUAS MANIFESTAÇÕES EM UMA INSTITUIÇÃO EMPRESARIAL
}

\section{MANAGERIALISM IN UNIVERSITY MANAGEMENT: AN ANALYSIS OF ITS MANIFESTATIONS IN A CORPORATE INSTITUTION}

\author{
Bernardo Meyer, Doutor \\ Centro Universiário Estácio de Sá de Santa Catarina \\ bernardo.meyer@estacio.br \\ Victor Meyer Junior, Doutor \\ Pontifícia Universidade Católica do Paraná - PUCPR \\ victormeyerjr@gmail.com
}

Recebido em 23/abril/2013

Aprovado em 05/agosto/2013

Sistema de Avaliação: Double Blind Review

Esta obra está sob uma Licença Creative Commons Atribuição-Uso. 


\title{
RESUMO
}

As instituições de educação superior estão sendo desafiadas pelas inúmeras mudanças impostas pelo seu ambiente de atuação. No Brasil esta realidade é representada pelo aumento do número de instituições de educação superior e o fortalecimento de grupos estrangeiros no setor. A ausência de abordagens próprias e a necessidade de maior eficiência e desempenho têm feito com que muitas instituições incorporem práticas gerenciais empresariais na gestão universitária. No Brasil este fenômeno é recente e seus efeitos são ainda pouco conhecidos. $\mathrm{O}$ objetivo deste trabalho é analisar o impacto da adoção de práticas gerenciais, de origem empresarial, identificadas como "managerialism" na gestão acadêmica de uma instituição de educação superior de caráter empresarial. Trata-se de um estudo de caso qualitativo, aplicado a uma das maiores instituições privadas de ensino superior. Os principais resultados indicam claras limitações das abordagens empresariais de gestão quando aplicadas à área acadêmica. A prática gerencial concentra-se na mensuração de algumas variáveis mensuráveis e seus resultados práticos ainda são pouco evidentes, gerando frustrações e desapontamentos entre gestores e stakeholders. As conclusões indicam que o desempenho de uma instituição educacional resulta de um grande número de variáveis tangíveis e intangíveis dificultando a medição dos resultados e do valor agregado.

Palavras-chave: Managerialism. Gestão Universitária. Instituições Privadas.

\begin{abstract}
Higher learning institutions are facing challenges due to the numerous changes imposed by their operational environment. In Brazil, this reality can be seen through the increasing number higher learning institutions and the strengthening of foreign groups in the sector. As there is no specific approach for university management and there is a need for greater efficiency and improved performance, many institutions have incorporated managerial business practices. In Brazil, this is as yet a relatively recent phenomenon and for this reason its effects remain largely unknown. The aim of this study is to analyze the impact of adopting managerial business practices, identified as managerialism, and implemented in the academic management by a proprietary higher education institution. It is a qualitative study, conducted at one of the largest private higher education institutions in Brazil. The main results show that business management approaches applied to the academic field are limited. Managerialism concentrates on measuring measurable variables and there is little evidence of their practical results, causing frustration and disappointment among managers and stakeholders. The conclusions indicate that the performance of an educational organization is the result of a large number of tangible and intangible variables that hinders the measurement of results and the value added.
\end{abstract}

Keywords: Managerialism. University Management. Proprietary Institutions. 


\section{INTRODUÇÃO}

A educação superior constitui-se em importante segmento da sociedade em razão do papel que desenvolve e de seu impacto nas atividades econômicas, políticas, culturais e sociais. Neste setor se concentra, atualmente, uma variedade de instituições públicas, religiosas, comunitárias e empresariais que competem por alunos, prestígio e recursos. Transformações no contexto econômico, social, tecnológico e educacional, além da expansão do número de instituições de educação superior - IES, nos últimos 20 anos, têm desafiado as instituições e contribuído para mudanças de suas políticas e ações. Dentre essas mudanças destaca-se a "corporativização" da educação superior que se fundamenta na incorporação do modelo empresarial como referência para gestão das instituições poderem enfrentar seus desafios, competirem e cumprirem sua missão. Segundo essa perspectiva há uma grande similaridade entre as organizações em geral o que permite a adoção de modelos e abordagens gerenciais voltadas para a otimização quanto ao uso de recursos o que contribui para um melhor desempenho na forma de maior competitividade e retorno do investimento.

Públicas, privadas ou empresariais as instituições educacionais possuem, por um lado, uma missão social relevante e, de outro, custos operacionais crescentes e recursos limitados para finalidades tão importantes e altruísticas. A procura por maior eficiência administrativa em organizações educacionais tem sido uma preocupação constante dos gestores universitários. Muitas instituições, em especial do setor privado, têm buscado nas empresas modelos e abordagens gerenciais visando melhoria de desempenho e diferencial competitivo.

A “corporativização" da educação superior é uma realidade em diversos países com destaque para países como Estados Unidos da América e Inglaterra. Porém, ainda são poucas as evidências empíricas da efetiva contribuição desta "cultura gerencial", que incorpora várias abordagens de gestão às organizações educacionais, em particular às instituições de educação superior.

Assim, o objetivo deste trabalho é analisar o impacto da adoção de práticas gerenciais, de origem empresarial, aqui identificadas como "managerialism”, na gestão acadêmica de uma instituição de educação superior de caráter empresarial. O referencial teórico fundamenta-se nas contribuições de autores que tratam das organizações educacionais como sistemas complexos, como anarquia organizada e modelo "lata de lixo" (COHEN; MARCH, 1974); sistema político (BALDRIDGE, 1971); sistema frouxamente articulado (WEICK, 1976; 1982); administração acadêmica (KELLER, 1983) e organização profissional 
(MINTZBERG, 1994; 2007) e seu impacto na gestão universitária. Com este estudo espera-se também gerar novos elementos que subsidiem a discussão a respeito da aplicabilidade e eficácia de práticas gerenciais corporativas em instituições de educação superior.

\section{GESTÃO DE IES}

O tema da gestão não é novo na educação superior. Tradicionalmente há uma preocupação dos gestores universitários em buscarem as melhores práticas gerenciais refletidas na qualidade do desempenho organizacional e na excelência da educação oferecida. Contudo, é no setor privado da educação superior onde se identificam visíveis esforços e iniciativas voltadas especialmente para a maior eficiência destas organizações. Atraídos pela lucratividade no setor vêem-se observando, na última década, o aumento da concorrência no mercado de educação superior brasileiro, marcado, dentre outros aspectos, pela chegada de grupos educacionais estrangeiros.

O fenômeno da internacionalização de empresas educacionais é uma realidade que tem acirrado a competição em vários países (BLUMENSTYK, 2003; MEYER JUNIOR; MEYER, 2008). Apoiadas em estratégias, essencialmente, empresariais e voltadas para a conquista de novos mercados estes grupos reforçam a abordagem da "corporativização" na conquista de novos mercados pelo mundo.

Este mercado competitivo tem conduzido as IES a uma busca constante por diferenciais e vantagens competitivas. Muitas instituições têm utilizado formas mais eficientes de gerenciamento com o objetivo de tirar vantagens de oportunidades no mercado, diferenciar-se de seus concorrentes e se tornar mais competitivas. A maior parte dessas abordagens tem seu gênesis e prática no mundo empresarial. Na ótica de Lamal (2001) muitas das transformações pelas quais estão passando as instituições educacionais resultam de um movimento de "corporativização" da educação superior.

Nesse particular destaca-se um fenômeno disseminado no mundo capitalista e largamente praticado pelas empresas denominado managerialism. Como apontam Locke e Spender (2011, p. 3) sua origem remonta a fins do século 19 e o início do século 20 com a gestão do chão de fábrica e a introdução da "administração cientifica de Frederic W. Taylor centrada na eficiência, produtividade e no individualismo. Este fenômeno se manifesta, por meio de um espírito orientador de práticas gerenciais muitas vezes predatórias que privilegiam mercados e negócios, como alvo para ser explorado a despeito de eventuais 
conseqüências e misfortunios. Por detrás deste conceito, segundo Quiggin (2003) repousa a crença de que há mais similaridades do que diferenças entre as organizações o que facilita a otimização do desempenho organizacional por meio da aplicação de teorias e de práticas de gestão.

Managerialism para Stacey (2010, p. 45) está relacionado à noção de administração como uma ciência ensinada nas escolas de administração com base em técnicas racionais analíticas necessárias para a maximização de lucros das empresas. Isto implica, segundo o mesmo autor, que este tipo de ciência pode não só ser ensinada, mas também aplicada em todos os tipos de organização. Neste sentido, para Stacey (2010, p. 45) os "gestores são guardiões dos recursos pertencentes a sociedade e que agem em nome de todos os stakeholders".

A busca por maior eficiência administrativa e rentabilidade nas organizações educacionais tem se constituído em tema polêmico provocando debates internos nas instituições, assim como tema de concorridos eventos que abordam a gestão das instituições de educação superior. Enquanto que para alguns a necessidade de garantir a sobrevivência da organização é a principal estratégia, para outros a busca por eficiência e lucratividade, com a adoção de modelos corporativos, ocorre à custa de uma baixa qualidade de educação.

A gestão de instituições de educação superior vem ganhando maior atenção na medida em que grandes investimentos são realizados, aquisições e fusões de instituições começam a ocorrer no setor exigindo maior profissionalização no seu gerenciamento para o alcance dos resultados esperados. A pressão gerada pelo ambiente competitivo tem exigido maior preocupação com eficiência e eficácia, além de uma preocupação de parte do governo que supervisiona o sistema de educação superior e a própria sociedade com a qualidade dos serviços educacionais prestados. Isso tem feito com que modelos empresariais sejam implantados com objetivo de se obter um melhor gerenciamento, na maioria das vezes sem qualquer ajuste às características complexas das IES.

Tradicionalmente as IES têm sido gerenciadas por profissionais não preparados para gerenciar organizações complexas com características únicas. Esta dicotomia já era descrita por Simon (1967) ao afirmar que as instituições de educação superior são voltadas para a formação de profissionais, mas são administradas por amadores. Isto pode ser atribuído ao fato dos seus gestores, em sua esmagadora maioria, serem acadêmicos, sem maior preparação para o desempenho de cargos gerenciais. Esse perfil típico de ocupantes de cargos gerenciais 
em organizações acadêmicas costuma caracterizar-se por práticas amadoras caracterizadas por decisões baseadas em sentimentos, percepção ou feeling, ou até mesmo de natureza negociada.

A importação de modelos de gestão do meio empresarial vem sendo uma das formas encontradas pelas IES para buscar mais rápidos e melhores resultados gerenciais. Esta prática, porém, não é feita de forma muito amistosa e tem gerado intensos debates no interior das próprias instituições em várias partes do mundo onde o fenômeno da privatização da educação superior se faz presente.

Várias são as razões que distinguem as instituições de educação superior de outros tipos de organização. Baldridge (1971) e Baldridge e Deal (1983) já destacavam que a universidade é um tipo de organização única por apresentar características singulares como: a) objetivos ambíguos e difusos; b) tecnologia complexa; c) usuários com necessidades individualizadas; d) profissionais com dupla lealdade; e) sensibilidade ao ambiente. Balderston (1995) reforça a singularidade das universidades ao destacar o seu papel triplo como organização, instituição e agência de desenvolvimento. Este mesmo autor enfatiza ainda a relevância de se examinar o trabalho das IES e seu impacto na sociedade.

Ainda no tocante às características das IES vários consagrados autores destacam dimensões ou aspectos desta complexidade. Assim, para Baldridge (1971), as universidades são exemplos, em escala menor, do sistema político existente na sociedade. Essas instituições, de acordo com o autor, se caracterizam por objetivos ambíguos; clientes com necessidades individuais distintas; tecnologia problemática; trabalho acadêmico essencialmente profissional, além de fragmentação em áreas e especialidades; e vulnerabilidade a fatores externos. Ao examinarem a realidade das IES, Cohen e March (1974) identificaram uma "anarquia organizada", referindo-se a um ambiente confuso, com pouca coordenação de objetivos e ações, processo decisório complexo e ausência de maior controle, portanto, distinto de uma burocracia organizada derivada do modelo weberiano e caracterizada por hierarquia clara, regras, profissionalismo e por impessoalidade nas relações.

Significativa contribuição teórica foi apresentada por Weick (1976) ao categorizar as organizações educacionais como "sistemas frouxamente articulados". Esse conceito reflete uma organização que se estrutura em áreas de estudo diferenciadas que desfrutam de ampla autonomia de atuação e com fraca integração entre elas. Weick (1976) refere-se à ausência, na organização, de uma coordenação, bem como a existência de uma fraca integração e 
interdependência entre as unidades que compões a área principal de produção: a acadêmica. Uma vez que a natureza do trabalho acadêmico é, essencialmente, intelectual e, portanto, de natureza qualitativa, seus resultados intangíveis, o controle e a mensuração do desempenho organizacional se transformam em enorme desafio aos gestores universitários.

Devido às particularidades próprias de uma organização complexa, seria impensável a uma organização educacional importar modelos gerenciais das empresas. Ao contrário, seria necessário criar formas próprias de gestão que contribuíssem, efetivamente, ao desempenho desejado. Neste particular Hardy et al. (1983), Mintzberg (1994; 2007) já alertavam que abordagens racionais, como o planejamento estratégico, não se adequavam ao contexto acadêmico devido às suas características especiais e complexidade. No entanto, na ausência de técnicas próprias o que acaba se vendo nas IES são adaptações e experimentações dos modelos empresariais (MEYER JUNIOR, 2003; MEYER JUNIOR; LOPES, 2006).

\section{GESTÃO ACADÊMICA}

A gestão acadêmica é um elemento de importância central na administração de qualquer organização educacional, em particular as instituições de educação superior. Cabe a ela a coordenação das atividades essenciais neste tipo de organização - o processo de ensino e aprendizagem. Promover um ambiente para que este processo seja eficaz fazendo com que aprendizagem ocorra constitui-se em objetivo precípuo da administração acadêmica.

O avanço das instituições de educação superior privadas e a incorporação de práticas empresariais de gestão têm produzido questionamentos sobre a adequação destas abordagens à realidade complexa da área acadêmica e dúvidas quanto às possíveis contribuições a geração de uma educação de qualidade. É comum ouvir o argumento de que ambas as coisas seriam incompatíveis, uma vez que a busca pelo lucro na educação viria acoplada ao sacrifício da qualidade na educação.

Outro fator que leva as universidades a resistirem à incorporação de modelos gerenciais deve-se, essencialmente, a sua origem corporativa. As empresas são vistas, dentro das universidades brasileiras, como organismos que viabilizam um capitalismo excludente (VERGARA, 2000). Esta percepção, com todo o seu forte viés ideológico, ainda se faz presente nas instituições de educação superior brasileiras constituindo-se em foco de resistência à inovações gerenciais de inspiração empresarial. 
Outra razão é a tendência natural dos gestores em manter o status quo e os padrões atuais de gestão aos quais já estão familiarizados rejeitando mudança e inovações. Ao estudar as universidades corporativas, Vergara (2000) reforça o entendimento de que uma das fontes de resistência existente entre universidades e empresas no Brasil pode ser claramente observada pelo fato de existir um reduzido número de parcerias entre estes dois tipos de organizações, ao contrário do que ocorre em países como Canadá e Estados Unidos da America.

Keller (1983) ressalta a importância do planejamento e da estratégia para o desenvolvimento acadêmico de uma instituição de educação superior. Na percepção do autor a gestão acadêmica não pode negligenciar aspectos mercadológicos e mudanças ambientais que afetam a organização e precisam adequar-se a elas.

Para Juliatto (2005) é fundamental a utilização de ferramentas de avaliação como um conceito-chave para se atingir melhores resultados na gestão acadêmica. A mensuração do grau de sucesso da instituição fornece elementos que irão permitir mudanças gerenciais voltadas para a melhoria dos resultados acadêmicos. Na mesma linha de argumentação Balderston (1995) destaca que o desempenho de uma universidade é medido em função de seus indicadores acadêmicos. A busca por classificações acadêmicas, nos rankings das melhores instituições, tem sido uma constante nas universidades por representar uma comprovação da qualidade acadêmica da instituição.

A gestão acadêmica precisa ser conduzida de maneira a gerar reflexos palpáveis na qualidade final do serviço que a organização educativa oferece a sociedade. $\mathrm{O}$ objetivo final da gestão acadêmica precisa ser sentido pelos alunos dentro da sala de aula. Para tanto, muitas ações e estratégias podem ser desenvolvidas, no que tange a melhoria de aspectos físicos e humanos.

Neste particular Bowman (2003) destaca que instituições de educação superior diferenciadas, em termos de propósitos, apresentam comportamento distinto. Conseqüentemente, a gestão acadêmica destas organizações tende a ser distinta na medida em que perseguem objetivos distintos. Por outro lado, a ambigüidade de objetivos e tecnologia indefinida enfatizadas por Baldridge (1971) e reforçadas por Cohen e March (1974) constituem-se, neste tipo de organização, em barreiras para a operacionalização de abordagens gerenciais oriundas das empresas. Para Weick (1976; 1982), o fato das organizações educacionais serem "sistemas frouxamente articulados" faz com que modelos gerenciais 
baseados em empresas entendidas como "sistemas justapostos" não tenham aplicabilidade no contexto das organizações educacionais.

A expansão do setor privado e a acirrada competição da educação superior brasileira fez com que gestores universitários se voltassem para a importação de modelos e abordagens gerenciais do setor empresarial. Muitas são as razões reforçam este comportamento inspirado em uma racionalidade instrumental voltada para a eficiência, produtividade e lucro, próprias das empresas e nas similaridades entre empresas e universidades.

Para Meyer Junior e Lopes (2008) a ausência de modelos próprios na gestão educacional contribui fortemente para este comportamento dos gestores. Outro fator é a chegada à governança das organizações educacionais de gestores vindos do setor empresarial que, baseados em sua experiência profissional e modelo mental passam a incorporar abordagens gerenciais próprias de sistemas mecanicistas. Nessas predominam a racionalidade, hierarquia, linearidade, poder centralizado e cujos principais resultados do esforço produtivo são medidos por valores monetários. Decorre daí um conflito de duas lógicas: uma primeira voltada para o mercado e, uma segunda, centrada em princípios e valores da academia fato que tem gerado inúmeros conflitos nas instituições educacionais empresariais em termos de diretrizes, estratégias e ações organizacionais.

Uma vez que as organizações educacionais não apresentam tais características os modelos típicos de gestão empresarial não se aplicariam à realidade dessas organizações. Por essa razão o uso equivocado destas abordagens gerenciais tem sido ineficaz e provocado frustração aos gestores e gastos desnecessários às organizações educacionais.

\section{METODOLOGIA}

Este trabalho caracteriza-se como um estudo de caso, de natureza qualitativa e descritiva (GODOY, 2007). Buscou-se, por meio desse estudo, analisar a experiência da empresa educacional Gama Investimentos na introdução de uma gestão com características empresariais nas suas instituições de educação superior. O nome da organização estudada é fictício para evitar a sua identificação e manter seu anonimato.

O estudo de caso, como abordagem metodológica, permite ao pesquisador analisar elementos ou fatores presentes em determinado contexto organizacional contribuindo para o aprofundamento do objeto estudado (CRESWELL, 2009; YIN, 1993; REMENYI et al., 1998). 
O nível de análise utilizado foi organizacional tendo como foco de estudo o Centro Universitário Gama e a unidade de análise baseada na percepção dos gestores da organização quanto às abordagens gerenciais, de cunho empresarial, adotadas a partir da integração da instituição à rede Gama Investimentos.

O Centro Universitário Gama, uma IES pertencente à rede de unidades educativas da Gama Investimentos, tem a sua localização na cidade de Porto Alegre, no Estado do Rio Grande do Sul. A faculdade conta com 12 diferentes cursos de graduação, cursos de especialização latu senso, cursos de extensão à comunidade e cursos de educação à distância. Em 2010 a unidade conta com aproximadamente 4.500 alunos em seus cursos presenciais e 900 alunos em seus cursos à distância.

A decisão de estudar a Gama Investimentos deveu-se ao fato desta organização educacional se constituir, atualmente, em um dos maiores grupos educacionais atuando no Brasil. A escolha concentrou-se no Centro Universitário Gama por se tratar da instituição que, dentre todas aquelas pertencentes à rede da Gama Investimentos, obteve o maior desempenho no ENADE de 2010.

A pesquisa baseou-se em dados primários e secundários. Os dados primários foram coletados por meio de entrevistas semi-estruturadas aplicadas a quatro (4) gestores acadêmicos e que integram o quadro gerencial da instituição. As entrevistas aconteceram no período de março a maio de 2011.

Os dados secundários foram obtidos mediante análise de publicações da instituição assim como normas e diretrizes administrativas oriundas da administração central da rede Gama Investimentos. Além desses foram utilizados planos, relatórios de atividades, apresentações e comunicações internas, além de informações sobre a instituição publicadas em fontes públicas de consulta, como jornais, revistas além de consulta aos próprios sites da organização foco do estudo e da holding do sistema.

A observação não participante constituiu-se na terceira fonte de coleta de dados. O fato de um dos pesquisadores ter tido a oportunidade de integrar o corpo docente e administrativo da instituição estudada permitiu o acesso privilegiado a informações obtidas em reuniões formais e conversas informais, dentre outras fontes. Estas informações contribuíram decisivamente para enriquecer o conteúdo do trabalho permitindo uma melhor observação e interpretação da realidade contribuindo assim para uma análise mais aprofundada das intenções e práticas gerenciais desenvolvidas. 
O estudo teve como foco de análise as seguintes inovações gerenciais adotadas na área acadêmica da instituição estudada: (a) Estrutura administrativa; (b) Políticas acadêmicas; (c) Controle sobre as atividades acadêmicas; (d) Programas de incentivo à qualidade docente; (e) Expansão da rede com aquisição de novas IES. A quase totalidade dessas mudanças gerenciais implementadas resultou de decisões estratégica tomadas pela holding do grupo Gama e que abrangeram todo o sistema educacional do grupo. O estudo abrangeu o período de 2008 a 2010 que corresponde ao espaço de tempo em que a Gama Investimentos assumiu o controle das operações da organização passando a adotar, de forma clara e objetiva, novas práticas gerenciais em suas unidades acadêmicas.

Os dados foram analisados por meio de técnicas de análise de conteúdo (BARDIN, 2010) e análise documental. A variedade de métodos utilizados permitiu o uso da triangulação, recomendada por Eisenhardt (1989), Yin (1993), e Martins e Theóphilo (2009).

\section{APRESENTAÇÃO DO CASO}

A Gama Investimentos é a empresa sucessora do antigo Grupo Gama, um império de instituições de educação superior espalhadas por todo o país. A empresa vem passando por um processo de intensas transformações desde o ano de 2008 quando trocou uma gestão familiar e passou a adotar uma gestão profissional. Desde então inúmeras mudanças tem ocorrido em todas as áreas da empresa visando dotá-la de maior competitividade e melhorar os resultados financeiros.

Estas mudanças introduzidas pelo novo grupo gestor apresentaram características típicas de "managerialism", ou seja, da transferência e incorporação de práticas gerenciais essencialmente empresariais nas organizações que compõem o sistema procurando alcançar maior racionalização na gestão e melhor desempenho da organização.

O resultado deste processo foi que a Gama Investimentos tornou-se uma das empresas educacionais que mais avançou em práticas gerenciais empresariais dentre as instituições que compõem o sistema privado empresarial de educação superior. Ênfase especial foi dada a planos traçados pela administração superior definindo objetivos e metas na busca de maior produtividade, eficiência e, sobretudo, melhores resultados organizacionais. As transformações foram sentidas por todos, uma vez que foi introduzida uma cultura organizacional fortemente voltada à eficiência com redução de custos, maior produtividade, 
aumento de base de alunos e foco em objetivos desafiantes que levaram a resultados concretos.

Estratégias como a redução de níveis hierárquicos e a centralização de serviços tiveram como propósito promover redução de custos e economias de escala e constituíram-se nas primeiras mudanças ocorridas. Assim a administração central da empresa, em Porto Alegre, centralizou todas as atividades de back office, reduzindo a necessidade de pessoal nas diversas unidades do sistema.

Todo o esforço de mudança na gestão da organização foi acompanhado por novas políticas na área acadêmica. Assim foram instituídos estímulos financeiros aos gestores acadêmicos bem como a professores com melhor desempenho, identificados com base na avaliação institucional e avaliação docente. A nova política acadêmica teve também o objetivo de proporcionar condições de melhoria de desempenho a aqueles professores que não apresentam desempenho adequado.

Uma frase muito repetida pelo Presidente da Gama Investimentos sintetiza a sua preocupação com ensino: "É dentro de sala de aula que se ganha o jogo". Embora a comunicação do dirigente ressaltasse a sala de aula como foco principal da atividade acadêmica do sistema pode-se identificar conflito em o discurso e ações praticadas. Se por um lado, havia uma declarada preocupação em atender às necessidades e expectativas dos alunos, por outro, ações gerenciais conduziam a um jogo em que o aluno, como cliente, fazia exigências e a organização buscava atender as demandas oferecendo serviços educacionais a um menor custo operacional.

As principais mudanças na área acadêmica foram a unificação dos currículos de todos os cursos em todas as instituições do sistema, bem como a incorporação de práticas pedagógicas inovadoras, como a oferta de disciplinas à distância e atividades estruturadas. Os coordenadores de curso entrevistados foram unânimes em reconhecer que os professores da instituição rejeitaram estas mudanças. O descontentamento chegou também aos alunos, os quais continuaram a pagar o mesmo valor de suas mensalidades embora tivessem redução de aulas presenciais.

Para melhorar o desempenho das unidades acadêmicas, vistas como unidades de produção, se determinou metas desafiantes aos gestores acadêmicos visando aumentar o número de alunos em sala de aula. Essa política não foi bem recebida por alunos e por 
professores, uma vez que estes últimos passaram a lecionar para turmas maiores, em salas superlotadas, tornando sua atividade docente mais cansativa e extenuante.

As provas padronizadas em todas as unidades do sistema no país constituíram-se em outra medida implantada. Uma vez que as disciplinas foram padronizadas em todo o sistema, adotaram-se também as provas nacionalizadas. Essas tiveram como objetivo garantir que o professor da disciplina não se distanciasse do conteúdo programático proposto para a mesma em termos nacionais. Se, de um lado, ganhos de economia de escala foram obtidos assim como custos operacionais foram reduzidos por outro, perdeu-se a autonomia e flexibilidade próprias do processo de ensino e aprendizagem além de desconsiderar diferenças regionais em termos de perfil de aluno e professor.

A avaliação dos professores, por parte dos alunos e coordenadores passou a ser acompanhada também como forma de medição de desempenho. Com base nestas avaliações foram também estruturados programas de participação nos lucros de gestores acadêmicos e docentes. Os dados da avaliação docente foram cruzados com a remuneração do professor, de forma a identificar se professores com hora/aula mais elevada eram, realmente, aqueles que apresentavam melhor desempenho. Esta prática de avaliação reduziu o comodismo de muitos docentes, mas criou um clima desconfortável e de apreensão dentre os professores com desempenho ruim, já que esta condição poderia conduzi-los à imediata demissão ao final do semestre.

Outra característica marcante da nova gestão da Gama Investimentos foi a prática de estratégia de incorporação de outras instituições, visando ampliar a participação da empresa no mercado da educação superior brasileiro. A expansão da educação à distância também tem se constituído em estratégia marcante da administração da holding. Isto foi demonstrado pelos grandes investimentos realizados na consolidação de um modelo diferenciado de educação à distância. A partir de 2010, a organização passou a estender a educação à distância a todas as regiões do país oferecendo seus serviços, diversificando suas atividades e expandindo seu mercado.

\subsection{Análise e discussão}

Agostini (2010) examinou as principais estratégias adotadas pelos principais grupos educacionais que atuam no país, identificando as seguintes estratégicas da Gama Investimentos consideradas como responsáveis pelo seu desempenho no mercado da educação 
superior: a primeira refere-se à redução do número de cursos buscando otimizar recursos e evitar cursos que dêem prejuízos; a segunda destaca a centralização das atividades financeiras, jurídicas e recursos humanos visando gerar economias de escala; a terceira diz respeito ao fortalecimento da marca da instituição por meio de publicidade e propaganda; a quarta enfatiza o investimento e expansão do ensino à distância no grupo e, finalmente, a quinta estratégia destaca a aquisição de outras IES e aumentar a base de alunos.

Essas estratégias adotadas pela Gama Investimentos revelam a existência de uma clara prática gerencial voltada para conquista de novos mercados próprias do "managerialism". Pode-se identificar uma preocupação maior da administração do sistema, a quem cabe tomar as principais decisões estratégicas para o sistema, em atingir maior racionalidade e melhores resultados econômico-financeiros, muitas vezes em detrimento da qualidade acadêmica.

Também foi possível observar a predominância de uma abordagem gerencial voltada para resultados, em especial na área econômica e financeira. Isto reflete a típica mentalidade empresarial de uma organização educacional de capital aberto e com acionistas cuja expectativa é sempre e, principalmente, o retorno do investimento econômico-financeiro acompanhado da correspondente valorização das ações e pagamento de dividendos. Tal mentalidade já refletia uma cultura predominante disseminada na gestão da holding influenciada por uma equipe de gestores com experiência essencialmente do mundo empresarial. Esse tipo de orientação representa uma visão de educação como commodity, algo que pode ser vendido e transferido por organizações no mercado, sem maiores percalços, para usuários do sistema em distintas regiões e países.

Foi unânime entre os gestores entrevistados que os dirigentes do grupo não conhecem a área de educação. Muitos deles têm experiência, na área bancária e de varejo, em outras organizações controladas pela Gama Participações. Muitas das mudanças introduzidas pelos gestores podem ser atribuídas à falta de conhecimento na gestão de organizações educacionais.

Certamente esses fatores têm contribuído para uma forte adoção de modelos empresarias na organização, inclusive já utilizados em empresas controladas pela holding. Este fato corrobora o que já destacava Weick (1982), Meyer Junior (2003), Meyer Junior e Lopes (2006; 2008), e Meyer Junior, Pascucci e Mangolim (2012) de que a inexistência de modelos próprios de gestão de IES estimula a aplicação de modelos empresariais, em geral caracterizados por outro tipo de racionalidade e voltado a sistemas lineares e justapostos. 
A análise e discussão dos resultados permitiu que se façam inferências quanto ao impacto das práticas corporativas introduzidas na gestão acadêmica da instituição foco do estudo. A primeira delas trata do acirramento da disputa de poder entre as áreas acadêmica e financeira refletindo um choque das lógicas de mercado e acadêmica. Enquanto a primeira fundamenta-se em objetivos claros e desempenho mensurável, medidos por indicadores quantitativos, a segunda está relacionada ao trabalho qualitativo e subjetivo, de difícil mensuração que caracteriza a essência da produção acadêmica representada pelo ensino e aprendizagem e disseminação do conhecimento. Pode-se observar que avanços no desempenho financeiro da organização implicaram, quase sempre, em redução de recursos e impacto negativo na atividade acadêmica e na qualidade de seus resultados.

A falta de compreensão entre administradores financeiros e gestores acadêmicos corrobora o entendimento de Birnbaum (1989) ao identificar a dificuldade de diálogo entre esses dois grupos de colaboradores nas IES. No caso da IES estudada pode-se identificar uma clara tendência de se priorizar a área financeira sempre em detrimento da área acadêmica. Foi evidenciada, uma vez mais, a lógica empresarial voltada para o resultado financeiro predominando nas principais decisões da instituição. Aspectos acadêmicos como qualidade do ensino e valor agregado pela instituição aos seus alunos, ficaram relegados a um segundo plano o que revela, ao mesmo tempo, uma miopia do gestor e um risco ao assumir a possibilidade de comprometer a área acadêmica.

Uma segunda área de análise diz respeito à adoção de ações de redução de custos, as quais muitas vezes acabaram afetando, negativamente, a qualidade do ensino já que o principal item de despesa de uma organização educacional é a folha de pagamento do corpo docente. A percepção do gerente acadêmico diverge desta interpretação ao ressaltar que muitos professores demitidos, seguindo a estratégia de redução de custos, não haviam sido bem avaliados pelos alunos. O único fator que os mantinha nas funções eram as relações pessoais informais que cultivavam com seus gestores.

Um terceiro elemento foco de análise foi uma série de estratégias e práticas gerenciais voltadas para a obtenção de maior eficiência no uso dos recursos financeiros da IES. Ao implantar padrões essencialmente empresariais, alguns estímulos para o alcance de melhores resultados foram definidos de forma a motivar os gestores a atingirem as metas estabelecidas nos planos. Neste particular a utilização de práticas gerenciais, tais como centralização das atividades-meio, demissão de professores mal avaliados, aumento do número médio de alunos 
em sala de aula, substituição de aulas presenciais por aulas à distância e atividades de campo, geraram visível aumento de eficiência e a conseqüente melhoria no desempenho financeiro da IES.

No entanto, uma gestão eficiente e eficaz, em geral, não é suficiente para atrair alunos nem tampouco os levará a escolher uma determinada IES para seus estudos. Além do preço, outros fatores são críticos como tradição, localização, reputação e qualidade acadêmica na escolha por uma instituição de educação superior. Percebeu-se que todos os principais elementos estavam centrados na qualidade e prestígio acadêmicos da instituição. Alunos e a comunidade são importantes stakeholders, assim como o são os acionistas; por conseguinte, a qualidade do ensino ministrado e reputação acadêmica estão sempre a merecer uma maior importância de parte dos gestores da organização, sob pena de perda de competitividade, imagem e prestígio.

Aspectos mercadológicos e competitivos da instituição são sabidamente relevantes para qualquer IES privada (KELLER, 1983). Porém o que diferencia as instituições de educação superior é a qualidade acadêmica. Neste particular, a lógica racional subjacente às abordagens gerenciais que imperam nas empresas pouca ou nenhuma contribuição traz para a qualidade acadêmica. Novamente a complexidade organizacional (MINTZBERG, 1994; MINTZBERG, 2007), sua natureza e conhecidas características organizacionais (COHEN; MARCH, 1974; BALDRIDGE, 1971; WEICK, 1976; WEICK, 1982) fazem com que as abordagens gerenciais tenham pouca ou nenhuma contribuição efetiva à área acadêmica.

Dentre todas as práticas gerenciais desenvolvidas, aquela que apresentou o impacto mais negativo na área acadêmica foi a substituição de disciplinas presenciais por disciplinas ofertadas, via educação à distância. Esta também foi uma das práticas que apresentou mais significativa redução de gastos operacionais e ganhos na receita delas derivadas.

Essas medidas geraram enorme insatisfação por parte dos corpos discente e docente da instituição. O aumento do número de alunos por sala de aula também foi foco de irritação, com efeito negativo na atividade e qualidade do trabalho acadêmico. Outro fator negativo, com clara intenção de ganho de economia de escala, foi o aumento significativo do número de alunos sem o necessário ajuste em termos de espaço físico, metodologia de ensino, e a contratação de assistentes.

Tanto a substituição de disciplinas presenciais por disciplinas à distância e atividades de campo orientadas quanto o aumento de alunos em sala de aula podem ter contribuído para 
a melhoria do desempenho da instituição em especial seus indicadores financeiros, em um horizonte de curto prazo. No entanto, certamente não contribuíram para melhoria efetiva dos indicadores acadêmicos e da imagem institucional. Essas políticas estão na contramão do que destaca Balderston (1995), ou seja, as organizações universitárias necessitam sempre valorizar os seus indicadores acadêmicos.

Algumas práticas, de cunho positivo, foram desenvolvidas como a utilização da avaliação discente como um mecanismo de tomada de decisão acadêmica. Isso se aplicou particularmente quanto à alocação e distribuição de carga horária entre os professores bem como a introdução da remuneração variável como incentivo aos melhores professores colocados no ranking de avaliação.

\section{CONCLUSÃO}

A competição no mercado da educação superior é acirrada e a combinação de preço de mensalidade, localização, prestígio e qualidade do ensino influenciam as decisões da demanda. Decisões e ações são em geral cruciais para o crescimento organizacional e sustentabilidade.

Pode-se perceber que as políticas e estratégias de gestão implantadas tiveram seus maiores efeitos na melhoria do desempenho financeiro. Poucos benefícios podem ser identificados ligados à melhoria da qualidade acadêmica e da aprendizagem dos alunos.

Algumas das abordagens propostas foram inovadoras na gestão da IES e podem ser utilizadas para melhorar o desempenho desse tipo de organização. $\mathrm{O}$ caso estudado revelou que ocorreram ganhos de eficiência, decorrentes das várias das abordagens gerenciais empregadas, na atividade meio. Esses ganhos estiveram representados pela redução de custos operacionais e o conseqüente cumprimento de objetivos e metas ligadas a rentabilidade financeira da organização.

Observou-se que o "managerialism" praticado foi relevante para promover maior eficiência operacional e para aumentar os resultados financeiros, de curto prazo, em especial nas atividades administrativas, muitas vezes em detrimento da área acadêmica. Contudo o desempenho da organização, como instituição educacional, é medido, em sua essência, por variáveis qualitativas que escapam ao conteúdo das abordagens gerenciais empresariais voltadas para sistemas racionais, mecanicistas e justapostos. O desempenho organizacional é medido pelas transformações ocorridas nos alunos, na sua educação, em especial sua 
formação geral e profissional, valores, além de mudanças comportamentais. No entanto, na área acadêmica muitas das estratégias adotadas se mostraram ineficazes, não resultando na melhoria da qualidade da educação oferecida.

Pode-se observar que três fatores contribuíram para o comportamento gerencial adotado pela organização estudada. Primeiro, a lógica de mercado que orienta as principais decisões e práticas gerenciais; segundo, o desconhecimento dos gestores das características especiais que tornam as instituições educacionais complexas e únicas requerendo gestão adequada; e, finalmente, a falta de experiência do grupo diretor da Gama Investimentos, empresa holding a quem cabe tomar as principais decisões e políticas que orientam as ações estratégicas para o todo o sistema.

A profissionalização da gestão acadêmica é uma necessidade e que poderá ajudar as organizações educacionais na busca de modelos próprios de gestão e melhor desempenho. No entanto, é necessário que seus gestores se utilizem de modelos adequados a sistemas complexos como são as organizações educacionais. De outra forma estarão gastando recursos escassos e preciosos sem o esperado resultado, gerando frustrações e desapontamentos entre seus gestores e inúmeros stakeholders.

As instituições educacionais são muito complexas para serem gerenciadas por ferramentas racionais. Seu desempenho resulta de um grande número de variáveis tangíveis e intangíveis que se mesclam dificultando uma medição de seu impacto no desempenho organizacional, em especial quanto ao valor agregado pela educação aos indivíduos e sociedade.

Espera-se que este trabalho contribua para o debate em torno dos desafios gerenciais das instituições de educação superior e do uso de abordagens gerenciais adequadas. Essas devem contribuir para uma mudança do quadro atual procurando melhor equilibrar a lógica de mercado e seu desempenho econômico-financeiros com a lógica acadêmica centrada na real oferta de educação de elevada qualidade. Talvez aí resida o maior desafio a ser enfrentado.

\section{REFERÊNCIAS}

AGOSTINI, R. Esse tem que dar certo. Revista Exame, São Paulo, n. 14, ano 44, p. 60-62, ago. 2010.

BALDERSTON, F. E. Managing today's university: strategies for viability, change, and excellence. San Francisco: Jossey-Bass Publishers, 1995. 
BALDRIDGE, J. V. Power and conflict in the university. New York: John Wiley \& Sons, 1971.

BALDRIDGE, J. V.; DEAL, T. The dynamics of organizational change in education. Berkeley: McCutchan Publishing, 1983.

BARDIN, L. Análise de Conteúdo. Lisboa: Edições 70, 2010.

BIRNBAUM, R. How colleges work: the cybernetics of academic organization and leadership. San Francisco: Jossey-Bass, 1989.

BLUMENSTYK, G. Spanning the globe: higher education companies take their turf battles overseas. The Chronicle of Higher Education, 27nd Ed. Washington, D. C., june, 2003.

BOWMAN, W. Novos contextos e habilidades na gestão do ensino superior. In: MEYER JUNIOR, V.; MURPHY, J. P. Dinossauros, gazelas e tigres: novas abordagens da administração universitária. Florianópolis: Insular, 2003. p. 91-105.

COHEN, M. D; MARCH, J. G. Leadership and ambiguity: the American College president. 2. ed. Boston: Harvard Business School Press, 1974.

CRESWELL, J. W. Research design: qualitative, quantitative, and mixed methods approaches. Thousand Oaks: Sage Publications, 2009.

EISENHARDT, K. M. Building theories from case study research. The Academy of Management Review, v. 14, n. 4, oct., 1989.

GODOY, A. S. Estudo de caso qualitativo. In: GODOI, C. K.; BANDEIRA-DE-MELLO, R.; SILVA, A. B. (Orgs.). Pesquisa qualitativa em estudos organizacionais: paradigmas, estratégias e métodos. São Paulo: Saraiva, 2007. p. 115 - 146.

HARDY, C. et. al. Strategy formation in the university setting. Review of Higher Education, v. 6, n. 4 , p. 407-33, 1983.

JULIATTO, C. I. A universidade em busca da excelência: um estudo sobre a qualidade da educação. Curitiba: Champagnat, 2005.

KELLER, G. Academic strategy: the management revolution in American higher education. Baltimore: The Johns Hopkins University Press, 1983.

LAMAL, P. A. Higher education: social institution or business. Behavior and Social Issues, fall, 2001.

LOCKE, R. R.; SPENDER, J. C. Confronting managerialism: how the business elite and their schools threw our lives out of balance. New York: Zed Books, 2011.

MARTINS, G. A. THEÓPHILO, C. R. Metodologia da investigação científica para ciências sociais aplicadas. São Paulo: Atlas, 2009. 
MEYER JUNIOR, V. Novo contexto e as habilidades do administrador universitário. In: MEYER JUNIOR, V.; MURPHY, J. P. Dinossauros, gazelas e tigres: novas abordagens da administração universitária. Florianópolis: Insular, 2003. p. 173-192.

MEYER JUNIOR, V.; LOPES, M. C. Planeamiento universitario: mito y realidad. Boletín de Investigación Educacional, Santiago de Chile, v. 21, n. 1, p. 283-292, 2006.

MEYER JUNIOR, V.; LOPES, M. C. Gestión escolar: desafíos y alternativas gerenciales. Visiones de la Educación, Concepción, Chile, n. 13, p. 55-65, 2008.

MEYER JUNIOR, V.; MEYER, B. Estratégias de internacionalização da educação superior. In: DOMINGUES, M. J. C. S.; SILVEIRA, A. Gestão de ensino superior: temas contemporâneos. Blumenau: Edifurb, 2008. p. 111-126.

MEYER JUNIOR, V.; PASCUCCI, L.; MANGOLIM, L. Gestão estratégica: um exame em universidades privadas. Revista de Administração Pública, v. 46, n. 1, p. 49-70, 2012.

MINTZBERG, H. The rise and fall of strategic planning. New York: Free Press, 1994.

MINTZBERG, H. Tracking strategies: toward a general theory. Oxford: Oxford University Press, 2007.

QUIGGIN, J. Word for wednesday: "managerialism" (definition), 2003. In: LOCKE, R. R.; SPENDER, J. C. Confronting managerialism: how the business elite and their schools threw our lives out of balance. New York: Zed Books, 2011. p. 5.

REMENYI, D. et al. Doing research in business and management. London: Sage Publications, 1998.

STACEY, R. D. Complexity and organizational reality: uncertainty and the need to rethink management after the collapse of investment capitalism. 2nd Ed. New York: Routledge, 2010. p. 45.

SIMON, H. The job of a college president. Educational Record, v. 58, n. 69, winter, 1967.

VERGARA, S. C. Universidade corporativa: a parceria possível entre empresa e universidade tradicional. Revista de Administração Pública, Rio de Janeiro, v. 34, n. 5, set./out., p. 181$188,2000$.

WEICK, K. E. Educational organizations as loosely coopled systems. Administrative Science Quartely, n. 21, p. 1-19, 1976.

WEICK, K. E. Administering education in loosely coupled schools. Phi Delta Kappan, v. 63, n. 10, jun., p. 673-676, 1982.

YIN, R. K. Applications of case study research. Newbury Park: Sage Publications, 1993. 